\title{
Influence of cutting-edge modifications on the cutting process when machining Inconel 718
}

\author{
M. Zetek \& I. Zetková \\ Regional Technological Institute, \\ University of West Bohemia, Czech Republic
}

\begin{abstract}
The machining of Inconel 718 or Ni-based alloys is very important within industry. Inconel 718 is a material that is hard to machine, but it has excellent properties, such as high temperature tensile and shear strength, hardness and low thermal conductivity. These properties influence the cutting process and machining productivity. So, it is necessary to choose the correct cutting tool with the optimal kinematic geometry. In our case, carbide end mills were used with different edge microgeometries and edge qualities. Drag finishing (DF) with different modification processes was used for edge modifications and DF technology was used at different times of the tool production. This is influenced by the cutting edge radius, $\mathrm{K}$ factor, chipping and roughness. In this paper, all of these parameters are monitored during the process and will be correlated with the machined surface properties such as roughness, surface topography and micro hardness. During the machining, the cutting tool wear and cutting forces are monitored in order to give a full description of the cutting process.

Keywords: Inconel 718, edge quality, cutting force, tool wear.
\end{abstract}

\section{Introduction}

During the finishing or semi finishing of the Inconel 718 part, it is necessary to know how stable the cutting tool is during machining and how it is stressed [1]. The mechanical properties of metallic materials are very important and depend on their chemical composition and microstructure, which can be altered by various heat treatments or thermomechanical treatment processes [2]. A typical problem is cracking of the main edge which causes an increase of the cutting force, heat stress and decrease of the surface quality and of course cutting tool life [3]. This 
cracking is very often associated with deformation and friction at the tool-chip and tool-workpiece interface [4] where these parameters could very quickly be changed by the machining strategy and cutting tool geometry and microgeometry. Normally when the cutting tool with indexable inserts is used the main cutting tool edge angle $\kappa_{\mathrm{r}}$ is smaller than $45^{\circ}$, optimal is around $10^{\circ}$. It causes a decrease in the notch formation and an increase of the cutting tool life. But when corner machining with a monolith cutting tool this solution is not usable and a different way must be found. Today there are very usable methods for modification of the cutting tool edge. These methods influence the cutting tool microgeometry and influence the quality of the thin coating deposition and quality of the machined surface. In case of the cutting tool microgeometry the cutting edge radius, roughness of the rake and flank face, K-factor and chipping must be defined and influenced and the producer must find their optimal parameter compromise.

For monolith cutting tools, drag or stream finishing is used for the modification of the cutting wedge after cutting tool grinding, and after thin layer deposition the polishing process with the same device is used. But the polishing depends on the thin coating thickness and on the machined materials and the cutting strategy is not used in all cases. Because these methods reduce the surface parameters by only a small value it is necessary to choose an appropriate device. In our case the IFM G4 optical microscope was used because it allows measuring of all the parameters on the cutting tool workpiece [5].

\section{Experiments}

\subsection{Monitoring of the cutting edge}

Routinely, all of the parameters are evaluated throughout the whole process and during the machining, which is shown in Figure 1. During this process, all of the parameters change, as shown in Table 1. It is evident how the edge radius, roughness and $\mathrm{K}$-factor are changed and the cutting edge with required edge radius of $15 \mu \mathrm{m}$ was used for this. For the tests, eight different edge radiuses and modifications were used (see Table 2).

What is very important for the next test is monitoring all parameters in the area where the cutting tool wear will be increased, which is shown in Figure 2 - marked in coral red. In our case, it is $2 \mathrm{~mm}$ from the cutting tool tip and $0.1 \mathrm{~mm}$ from the main cutting edge.

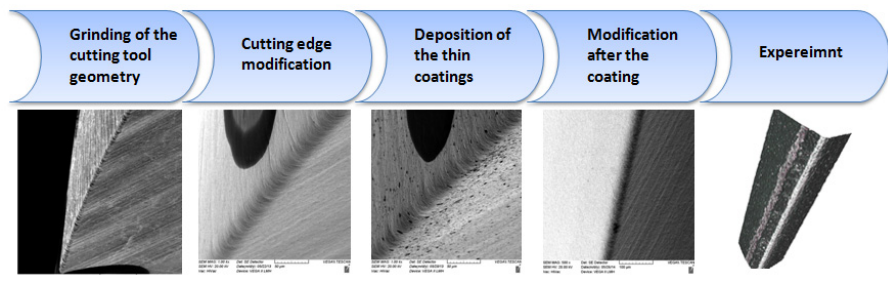

Figure 1: Process of the cutting edge modification and monitoring. 
Table 1: Progress of measuring values during process.

\begin{tabular}{|l|c|c|c|c|}
\hline & $\begin{array}{c}\text { After } \\
\text { grinding }\end{array}$ & $\begin{array}{c}\text { After } \\
\text { modification }\end{array}$ & $\begin{array}{c}\text { After } \\
\text { deposition }\end{array}$ & $\begin{array}{c}\text { After coating } \\
\text { modification }\end{array}$ \\
\hline Edge radius $\boldsymbol{\rho}_{\mathbf{r}}[\boldsymbol{\mu m}]$ & 2.5 & 14 & 17 & 17.7 \\
\hline K-factor $[1]$ & 0.91 & 0.89 & 0.88 & 1 \\
\hline Roughness $\mathbf{R}_{\mathbf{z}}[\boldsymbol{\mu} \mathbf{m}]$ & 0.9 & 0.43 & 0.37 & 0.46 \\
\hline
\end{tabular}

Table 2: $\quad$ Edge modification (N-without modification, L-lapping, C-coating, DF-drag finishing, P-polishing).

\begin{tabular}{|l|c|c|c|c|c|c|c|c|}
\hline No. of cutting tools & $\mathbf{E}$ & $\mathbf{5}$ & $\mathbf{1 0}$ & $\mathbf{1 5}$ & $\mathbf{1 5 a}$ & $\mathbf{1 5 b}$ & $\mathbf{2 0}$ & $\mathbf{2 5}$ \\
\hline Modification & $\mathrm{N}$ & $\begin{array}{c}\mathrm{L}+ \\
\mathrm{C}\end{array}$ & $\begin{array}{c}\text { DF } \\
+\mathrm{C}\end{array}$ & $\begin{array}{c}\text { DF } \\
+\mathrm{C}\end{array}$ & $\begin{array}{c}\text { DF }+ \\
\mathrm{P}+\mathrm{C}\end{array}$ & $\begin{array}{c}\text { DF }+ \\
\mathrm{C}+\mathrm{P}\end{array}$ & $\begin{array}{c}\text { DF }+ \\
\mathrm{C}\end{array}$ & $\begin{array}{c}\text { DF }+ \\
\mathrm{C}\end{array}$ \\
\hline Edge rad. $\boldsymbol{\rho} \mathbf{[ \boldsymbol { \mu m } ]}$ & 2.5 & 5 & 10 & 15 & 15 & 15 & 20 & 25 \\
\hline
\end{tabular}

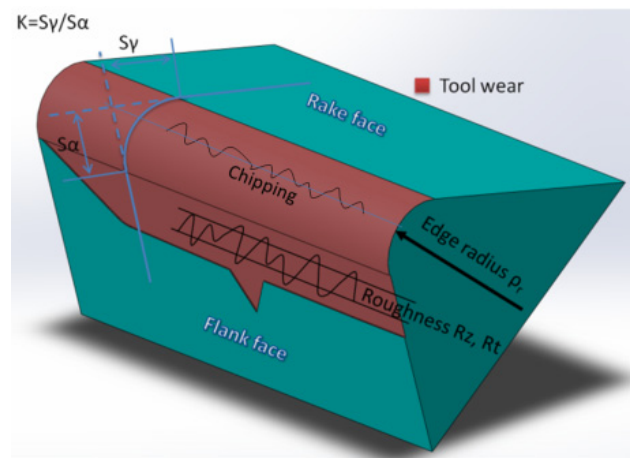

Figure 2: Monitored parameters on the cutting tool edge.

\subsection{Cutting tool life}

This chapter is focused on measuring the tool wear on the flank face VB, on monitoring the cutting forces and the workpiece quality. Two tooth mills from sintered carbide were used for the tests. For the evaluation of the tool wear, the Blickle Multicheck PC500 optical microscope and IFM G4 by Alicona Co. were used and the Kistler dynamometer was used to measure the cutting forces. The tool wear was also monitored at a distance of $2 \mathrm{~mm}$ from the mill tip.

Table 3: Cutting conditions.

\begin{tabular}{|c|c|c|c|c|c|}
\hline $\begin{array}{c}\text { Cutting speed } \\
\mathbf{v}_{\mathbf{c}}[\mathbf{m} / \mathbf{m i n}]\end{array}$ & $\begin{array}{c}\text { Feed speed } \mathbf{v}_{\mathbf{f}} \\
{[\mathbf{m m} / \mathbf{m i n}]}\end{array}$ & $\begin{array}{c}\text { Axial depth of } \\
\left.\text { cut } \mathbf{a}_{\mathbf{p}} \mathbf{[ m m}\right]\end{array}$ & $\begin{array}{c}\text { Radial depth of } \\
\text { cut } \mathbf{a} \mathbf{m}[\mathbf{m m}]\end{array}$ & $\begin{array}{c}\text { Cutting } \\
\text { environment }\end{array}$ & $\begin{array}{c}\text { Cutting tool } \\
\text { dia. ød [mm] }\end{array}$ \\
\hline 35 & 111 & 3 & 0.5 & $\begin{array}{c}\text { External } \\
\text { cooling }\end{array}$ & 8 \\
\hline
\end{tabular}




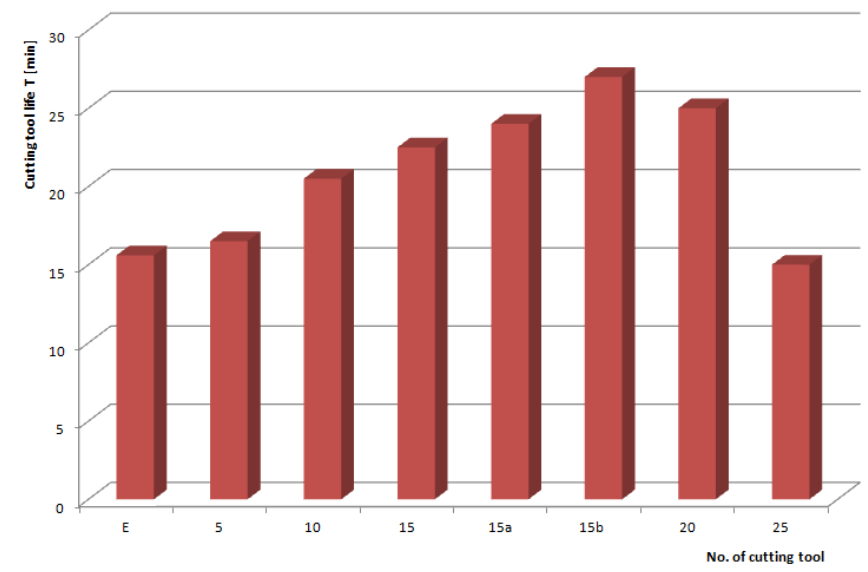

Figure 3: Influence of the cutting edge modification on the cutting tool life.

Many times when the cutting tool wear was measured on a standard Blickle optical microscope it was not evident if the value of the tool wear was correct (Figure 4, image 1) during measuring. In this case the IFM G4 microscope was used and Figure 4 shows the differences between both methods.
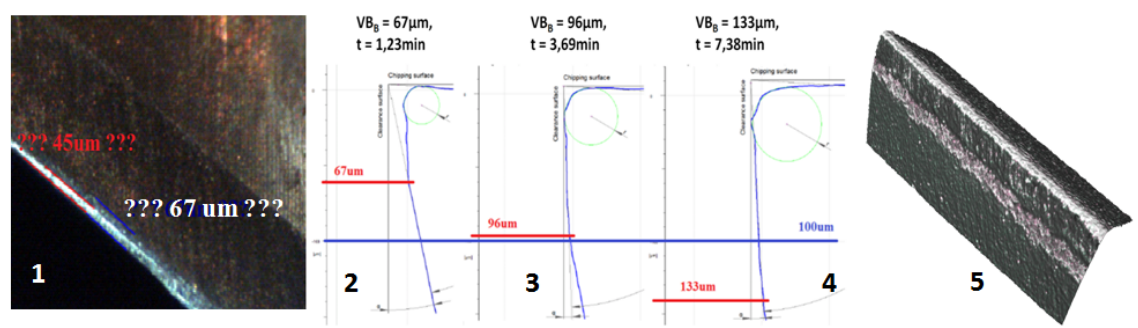

Figure 4: Measuring of the cutting tool wear; 1. Optical microscope Blickle; 2-5. IFM G4.

If the special option on IFM G4 is used it is possible with high accuracy to identify the maximum limit of tool wear. In the first step a 3D scan was made (Figure 4: image 5) where the abrasion wear was evident. The next step was to import to $2 \mathrm{D}$ view in one cut and measure the correct parameters. From the $3 \mathrm{D}$ scan it is possible to measure and evaluate the volume values which are used to determine if the cutting edge decreases or increases - creation of BUE. How it works is shown in Figure 5.

Figure 5 shows the comparison between the new cutting edge and the cutting edge with wear. The result is the colour spectrum with defined accuracy and a table with accurate values. If we need to know how many materials decrease or increase, these items are described by parameters $V_{V}$ and $V_{p}$. In this case, the dominant tool wear is abrasive because much more material is missing $\left(\mathrm{V}_{\mathrm{v}}\right)$ and the colour spectrum shows the same valley surfaces with depths of about $30 \mu \mathrm{m}$. 
The materials that are above the reference surface $\left(\mathrm{V}_{\mathrm{P}}-\right.$ yellow, orange, about 5 $\mu \mathrm{m})$ are probably a mixture of workpiece dust with cooling liquid and chip residues.

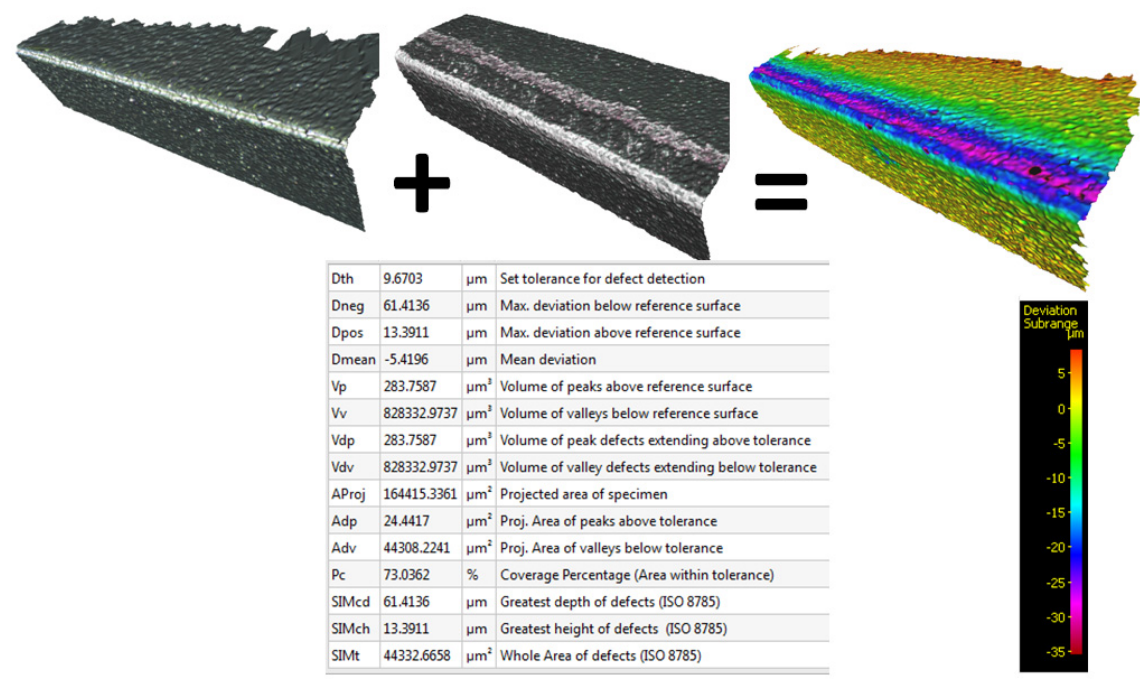

Figure 5: Identification of the tool wear process - abrasion vs. BUE.

\subsection{Cutting force}

Inputting different cutting edge modifications influences all monitoring values. Cutting tool life is very important information and in many cases it is a critical parameter for users. But if the surface quality is solved it is necessary to know other values such as cutting forces which influence surface morphology, stress, cracks, etc. For measuring these parameters a Kistler type 9255A dynamometer was used. In this case it is important to know the cutting forces at the beginning of the machining. At this time the cutting force is very clearly influenced by the edge modification and not by tool wear. This is shown in Figure $6-$ Fy 00 . When the edge radius is smaller (sharper) the cutting force is lower too. This corresponds with the theory and corresponds with the shape of the new cutting edge where the craters on the main cutting edge are created by the edge modification methods (Figure 7). The cratering causes an increase of the cutting force because it creates negative facets between the flank and face rake.

But at the end of machining, an analogy of maximum cutting force for the edge modification with edge radius higher than $10 \mu \mathrm{m}$ is evident. This is caused by the similar type of tool wear at the end. This conclusion could be made when the tool wear is compared using a standard optical microscope (Figures 1-4).

But if it is compared with $2 \mathrm{D}$ cuts in similar areas the results show other differences which are not evident on standard optical microscopes (Figure 8). This different type of tool wear does not influence the value of cutting forces but it influences surface microhardness and topography. 
76 Surface and Contact Mechanics including Tribology XII

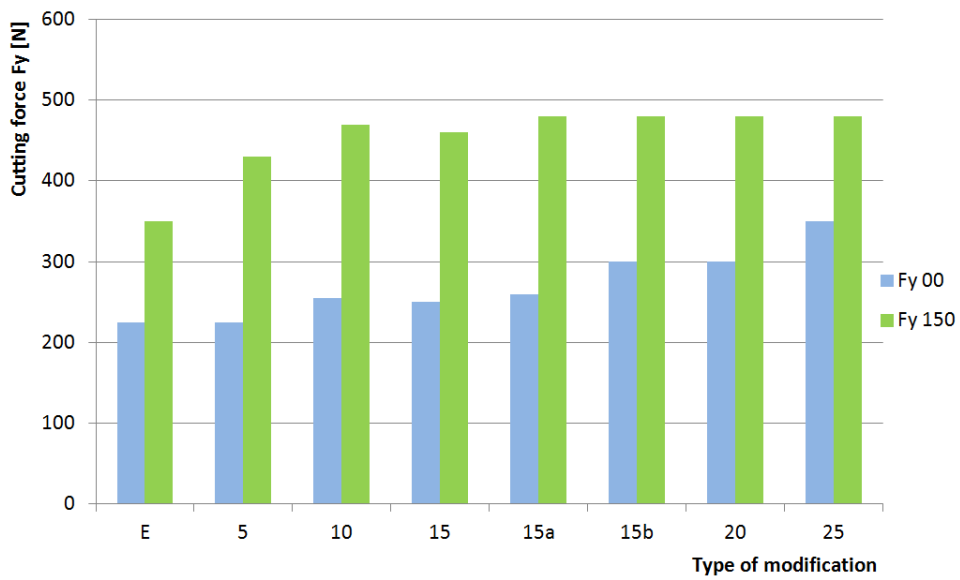

Figure 6: Influence of the edge modification on the cutting force Fy (Fy $00=$ cutting force at the beginning of machining; Fy $150=$ cutting force at the end of machining - max. limit of tool wear $\mathrm{VB}_{\mathrm{B}} 150 \mu \mathrm{m}$ ).

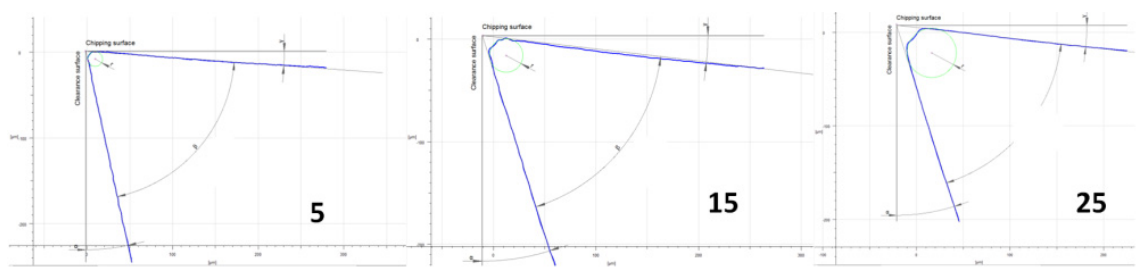

Figure 7: Accuracy cutting edge reliefs of different edge radius - 5, 15, 25 (after deposition before machining).
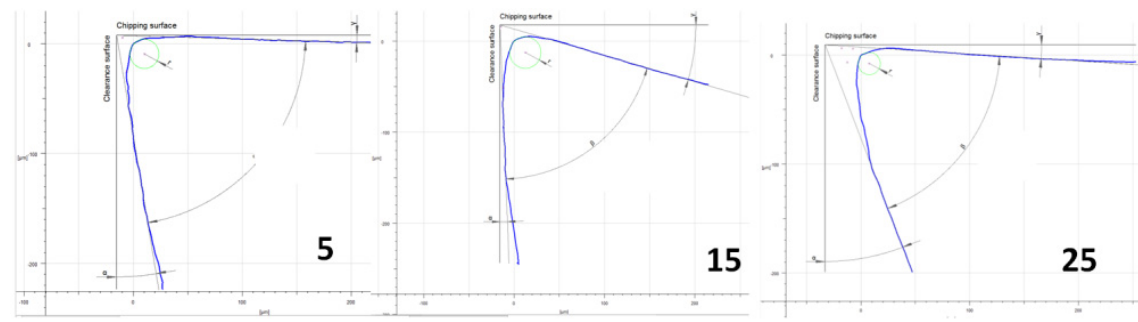

Figure 8: Accuracy cutting edge reliefs of tool wear, 2D cuts of 5, 15, 25.

\subsection{Surface quality}

In the first part the microhardness HV2 was evaluated. As in the case of cutting force evaluation, the surface hardness at the beginning was influenced by the clear edge modification without influence of the tool wear. So it was possible to determine the differences between the edge radius, as shown in Figure 9. 


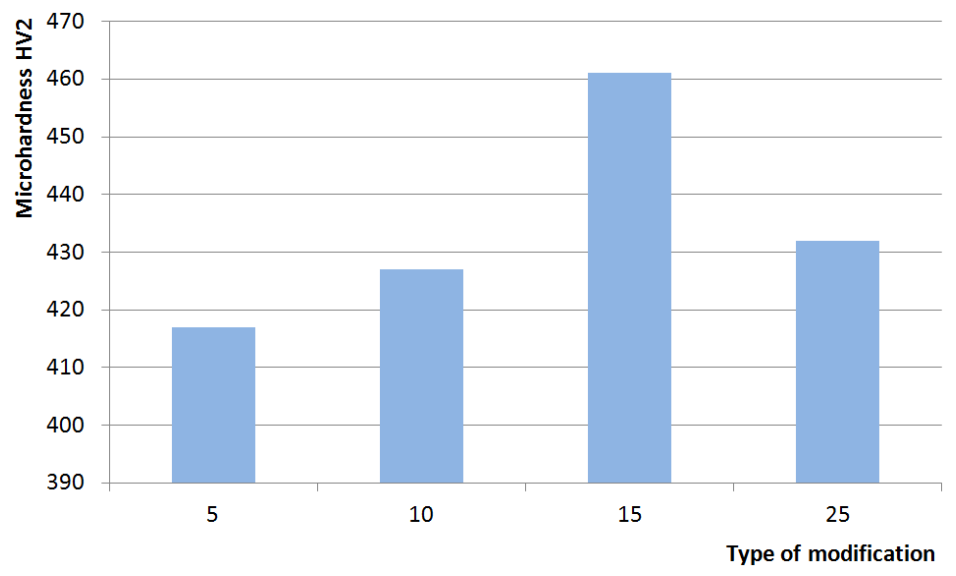

Figure 9: Influence of the edge radius on the surface microhardness (after first cut).

The different hardnesses are influenced by the real edge shape. The craters on the main cutting edge cause negative facets which influence these values. But for edge radius $25 \mu \mathrm{m}$ the hardness is lower than for the $15 \mu \mathrm{m}$ radius. When we focus on the microgeometry of these two radiuses (Figure 7) and compare it, a higher dimensional facet is evident on the radius of $25 \mu \mathrm{m}$ which is composed of a combination of two small functional radiuses and one facet. The $15 \mu \mathrm{m}$ radius looks similar in shape but the radiuses are too small and this causes large amounts of stress between the flank rake and the machined surface. At the end of machining (when the tool wear $\mathrm{VB}_{\mathrm{B}}$ is $150 \mu \mathrm{m}$ ) the results are different from the beginning of the process (Figure 10).

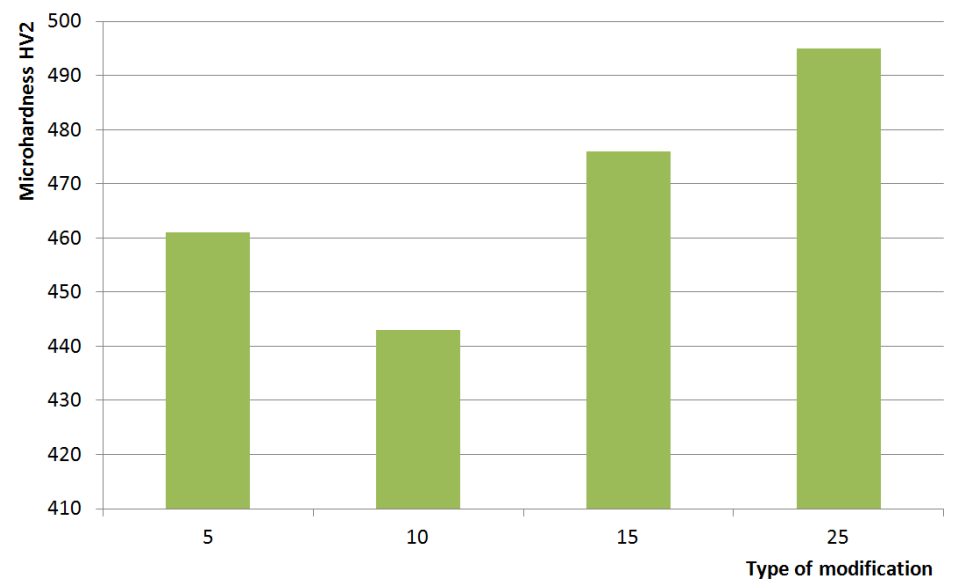

Figure 10: Influence of the edge radius on the surface microhardness (after last cut). 
This is caused by the real cutting edge shape, which is influenced by the cutting tool wear. How the edge looks, how it is deformed or if there is any abrasive wear and how many shapes are formatted on it are all very important factors. How these objects are oriented toward the cutting speed vector and the influence of the deformation of the machined surface are also important aspects.

Now, when we compare the surface topography after machining there are differences that depend on machining time and tool wear formation (Figure 11).
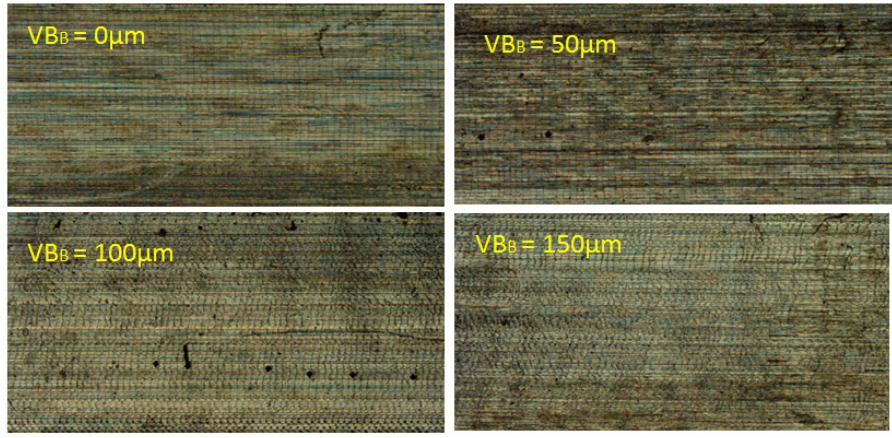

Figure 11: Influence of the tool wear on the surface topography.

At the beginning of machining, $\mathrm{VB}_{\mathrm{B}}=0 \mu \mathrm{m}$ regular objects are on the surface which have a linear structure. With more time and a higher tool wear these formations start to deform and change their structure from linear to chaotic. Moreover, these structures and their evolution depend on edge radius and tool wear formation during the time as in the case of microhardness. But if the profile roughness is measured there are similar values. It is strange because in the image it is evident that the shape is different. So in this case it is necessary to evaluate surface roughness where there are big differences. But this issue is for the next paper

Table 4: Value of profile and surface roughness.

\begin{tabular}{|l|c|c|c|c|}
\hline $\mathbf{V B}_{\text {B }}[\boldsymbol{\mu m}]$ & $\mathbf{0 0}$ & $\mathbf{5 0}$ & $\mathbf{1 0 0}$ & $\mathbf{1 5 0}$ \\
\hline $\mathbf{R a}[\boldsymbol{\mu m}]$ & 0.34 & 0.23 & 0.35 & 0.26 \\
\hline $\mathbf{S a}[\boldsymbol{\mu m}]$ & 50 & 14 & 42 & 6 \\
\hline $\mathbf{R z}[\boldsymbol{\mu m}]$ & 2.4 & 1.6 & 1.9 & 1.6 \\
\hline $\mathbf{S z}[\boldsymbol{\mu m}]$ & 21.4 & 22 & 24 & 13 \\
\hline
\end{tabular}

\section{Conclusion}

The main aim of this paper was to present some general information which influences the cutting process during machining Inconel 718. All these tests and monitoring methods are applicable when a different material is machined. It is very important to know what and where the final product will be used and how 
important is surface quality or production. At the beginning of this paper eight different edge modifications made by drag finishing were shown. It was evident how the small edge radius influences tool life, cutting surface, hardness of surface and other parameters. It is very important to know, because with a small modification of the edge microgeometry it is possible to define the influence of all parameters and obtain the optimizing process. For example, in our case if the surface quality is in first place, the best way is to use cutting tool number 10 or 25 . But if the customer needs a surface with best roughness (linear, surface r.) and topography it is necessary to use cutting tool number 10 . But in many cases the customer needs higher production, so in this case it is optimal to use cutting tool number $15 \mathrm{~b}$. Finally, these results are input values for the next steps and solution in the area of developing cutting tools and microgeometry for machining Ni-based superalloys.

\section{Acknowledgement}

This paper is based upon work sponsored by the project "Regionální technologický institut”, no. CZ.1.05/2.1.00/03.0093.

\section{References}

[1] M. S. Kasim, C. H. Che Haron, J. A. Ghani, M. A. Sulaiman, M. Z. A. Yazid, Wear mechanism and notch wear location prediction model in ball nose end milling of Inconel 718, Wear, volume 302, issues 1-2, April-May 2013, pp. 1171-1179.

[2] D. Aisman, H. Jirková, B. Masek, The influence of deformation and cooling parameters after transition through semi-solid state on structure development of ledeburite steel, Journal of Alloys and Compounds, Volume 536, Supplement 1, pp. S204-S207, Elsevire 2011, ISSN 0925-8388.

[3] T. Kitagawa, A. Kubo, K. Maekawa, Temperature and wear of cutting tools in high-speed machining of Inconel 718 and Ti6Al6V2Sn, Wear 202 (1997) pp. 142-148.

[4] E. O. Ezugwu, Key improvements in the machining of difficult-to-cut aero-space superalloys, International Journal of Machine Tools and Manufacture 45 (2005) 1353-1367.

[5] I. Česáková, M. Zetek, V. Švarc, Evaluation of Cutting Tool Parameters, Procedia Engineering, volume 69, 2014, pp. 1105-1114, Elsevire 2014, ISSN: 1877-7058. 